\title{
Skin Toxicities of Immune Check Point Inhibitors in Solid Tumors and Managment:
}

\section{Review of Literature}

\author{
Mohamed réda KHMAMOUCHE ${ }^{1}{ }^{2}$, Choukri Elmhadi', Tarik Mahfoud ${ }^{1}$, Rachid Tanz', Lamiaa Amaadour², Aziz \\ Bazine $^{3}$, Mohamed Fetohi ${ }^{3}$, Nawfel Mellas² and Mohamed Ichou ${ }^{1}$ \\ 'Medical oncology department, Military Hospital Mohammed V, Rabat, Morocco \\ ${ }^{2}$ Medical oncology department, Hassan II University Hospital, University Sidi Mohamed Ben Abdellah, Fes, Morocco \\ ${ }^{3}$ Medical oncology department, Military Hospital Moulay Ismail, Meknes, Morocco
}

*Corresponding author: Mohamed réda Khmamouche, Medical oncology department, Military Hospital Mohammed V, Rabat, Hassan II University Hospital, University Sidi Mohamed Ben Abdellah, Fes, Morocco

\section{ABSTRACT}

Skin toxicities are the most prevalent immune-related adverse events. Various reactions have been reported few weeks after initiation treatment by immune checkpoint inhibitors. In this review, we summarized the clinicopathologic manifestations of different lesions and principles of their management .

Keywords: Skin toxicities, pruritis, immune check point inhibitors, adverse events

\section{Introduction}

Immune checkpoint inhibitors (ICls) are currently used in the treatment of several cancers in adjuvant and metastatic situations such as melanoma, classical Hodgkin disease, urothelial carcinomas, non small cell lung cancers , renal clear cell carcinomas, Merkel cell carcinoma and cutaneous squamous cell carcinoma due to their inhibitory effects on cytotoxic T-lymphocyte-associated protein 4 (anti-CTLA4) or anti-programmed death-1 (anti-PD1) and its ligand (anti PDL-1) [1].

The most frequent immune related adverse events affect skin, endocrine organs, colon, liver and lungs. However, very serious lesions, even lethal, such as neurological disorders and myocarditis are rare [2-6].

Among the most frequently described cutaneous side effects in the literature, pruritus is frequently reported as a side effect of these treatments $[7,8]$, followed by rush and vitiligo [2]. Other toxicities have been reported more rarely with checkpoint inhibitors: alopecia areata, stomatitis, xerosis cutis, psoriasis and photosensitivity $[9,10]$. The principal aim of this review is to describe skin lesions in patients treated with ICls for solid tumors and to discuss the principles of their therapeutic management.

\section{Different ICls used in treatment of cancers}

Immune checkpoint therapy affects the anti-tumor immune response at the level of $T$ cell activation by antigen presenting cells (APCS). The CTLA-4 protein is expressed on $T$ cells, and competes with CD28 for linking up to B7 [11]. It is thus a competitive inhibitor of $T$ cell activation. Pharmacologic CTLA-4 inhibition increases binding of CD28 to $\mathrm{B} 7$ and there by promotes $T$ cell activation [11].

T cells also express the Programmed Death 1 receptor (PD-1), which is activated by PD ligands 1 and 2 (PD-L1 and PD-L2) to decrease T cell activation by inhibiting proliferation, decreasing cytokine production, and promoting apoptosis [11]. ICls are medications that act at the level of $\mathrm{T}$ cell costimulation to increase immune activation, with the goal of promoting an anti-tumor immune response. All ICls are monoclonal antibodies. Ipilimumab is the lone FDA-approved inhibitor of CTLA-4 [12]. However, there is a number of FDA approved PD-1 inhibitors : nivolumab and pembrolizumab. Combination CTLA-4 and anti PD- 1 has been shown to be more effective than monotherapy ; but, 
combination therapy may be substantially more toxic, and needs to select carefully patients [13].

The first use of $\mathrm{ICl}$ to achieve true remissions in metastatic melanoma was obtained with ipililumab. Inhibition of the PD-1 axis has found application in the treatment of a variety of solid tumors. Pembrolizumab and nivolumab are both approved for the treatment of non-small cell lung cancer and other solid tumors and hematologic malignancies [13]. Cemiplimab is a new PD- 1 inhibitor developed and is approved specifically for metastatic or unresectable squamous cell carcinoma [14]. In addition, atezolizumab, durvalumab and avelumab are PD-L1 inhibitors, approved for the treatment of many solid tumors including small and non-small cell lung cancers, urothelial carcinoma, and Merkel cell carcinoma [13]. The names of the main ICls approved by the FDA, and their indications are summarized in Table 1.

\section{Grading of immune cutaneous adverse events}

Adverse events can be classified by grades based on the degree of severity and associated morbidity. It is according The Common Terminology Criteria for Adverse Events (CTCAE). Familiarity with the CTCAE grading system is

Table 1: FDA approved ICl and their indications.

\begin{tabular}{|c|c|c|}
\hline DCI & Target & Indications \\
\hline ipilimumab & CTL-A4 & $\begin{array}{l}\text { Melanoma (unresectable/metastatic or Stage 3, first-line or adjuvant) } \\
\qquad \text { Renal cell carcinoma (combination with nivolumab) } \\
\text { - Metastatic colorectal cancer (microsatellite instability-high or mismatch repair deficient, second line)(w/ } \\
\text { nivolumab) }\end{array}$ \\
\hline Pembrolizumab & PD-1 & $\begin{array}{l}\text { Melanoma (unresectable/metastatic or Stage 3, first-line or adjuvant) } \\
\text { • Non-small cell lung cancer (first-line or second line, single agent orcombination, based on gene expression) } \\
\text { • Small cell lung cancer (third line) } \\
\text { • Head and neck squamous cell carcinoma (first-line or second line, single agent or combination, based on gene } \\
\text { expression) } \\
\text { • Classical Hodgkin Lymphoma (fourth-line) } \\
\text { • Primary mediastinal large B-cell lymphoma (third-line) } \\
\text { • Urothelial carcinoma (first or second line, based on gene expression) } \\
\text { • Microsatellite Instability-High cancer (second-line for colorectal, last-line for any other type) } \\
\text { • Cervical carcinoma (second-line, with compatible gene expression) } \\
\text { • Hepatocellular carcinoma (second-line) } \\
\text { • Merkel cell carcinoma (recurrent locally advanced or metastatic) } \\
\text { • Renal cell carcinoma (first line)(combination with axitinib) }\end{array}$ \\
\hline Nivolumab & PD-1 & $\begin{array}{c}\text { Melanoma (unresectable/metastatic or Stage 3, first-line or adjuvant) } \\
\text { - Non-small cell lung cancer (second- or third-line, based on gene expression) } \\
\text { • Small cell lung cancer (third-line) } \\
\text { • Head and neck squamous cell carcinoma (second-line) } \\
\text { • Classical Hodgkin Lymphoma (third- to fourth-line, post-transplant) } \\
\text { - Urothelial carcinoma (second-line) } \\
\text { - Hepatocellular carcinoma (second-line) } \\
\text { - Renal cell carcinoma (first-line with ipilimumab or second-line) }\end{array}$ \\
\hline Cemiplimab & PD-1 & Cutaneous squamous cell carcinoma (unresectable or metastatic) \\
\hline Atezoluzumab & PD L-1 & $\begin{array}{l}\text { Urothelial carcinoma (first- or second-line, based on gene expression) } \\
\text { - Non-small cell lung cancer (first-line in combination, second-line single,based on gene expression) } \\
\text { • Small cell lung cancer (first-line in combination) } \\
\text { • Breast carcinoma, triple-negative (first-line in combination) }\end{array}$ \\
\hline Avelumab & PD L-1 & $\begin{array}{c}\text { Merkel cell carcinoma (metastatic, first-line) } \\
\text { • Urothelial carcinoma (second-line) } \\
\text { - Renal cell carcinoma (first-line in combination with axitinib }\end{array}$ \\
\hline Durvalumab & PD L-1 & $\begin{array}{l}\text { Urothelial carcinoma (second-line) } \\
\text { - Non-small cell lung cancer (patients without progression after first-line therapy) }\end{array}$ \\
\hline
\end{tabular}

Citation: Mohamed réda KHMAMOUCHE ${ }^{1,2}$, Choukri Elmhadi ${ }^{1}$, Tarik Mahfoud ${ }^{1}$, Rachid Tanz ${ }^{1}$, Lamiaa Amaadour ${ }^{2}$, Aziz Bazine ${ }^{3}$, Mohamed Fetohi ${ }^{3}$, Nawfel Mellas ${ }^{2}$ and Mohamed Ichou ${ }^{1}$. Skin Toxicities of Immune Check Point Inhibitors in Solid Tumors and Managment: Review of Literature. 
important in communicating with a patient's oncology team and dermatologist. Depending the severity of cutaneous toxicity, we can grade maculopapular eruptions and bullous lesions on four grades: Macules/papules or blisters covering $<10 \%$ BSA is defined Grade1, grade 2 if covering 10 to $30 \%$ $\mathrm{BSA}$, and $>30 \%$ is defined grade 3 . Any life-threatening cutaneous toxicity is considered grade 4 [13-15].

\section{Skin Immunorelated Adverse Events}

Skin toxicities are the most common complications reported of $\mathrm{ICl}$ therapy and the earliest to occur. Many cutaneous irAEs present similarly to primary dermatoses and may share properties with autoimmune skin disorders [13]. Fortunately, these cutaneous adverse events are typically mild, and can usually be managed without interruption of immunotherapy [13].

The incidences of all-grade dermatologic immuno related adverse events range from $17 \%$ to $40 \%$ for PD-1/PDL1 inhibitors and $37 \%$ to $70 \%$ for ipilimumab, while grade 3 or higher cutaneous toxicities are found in $1 \%$ to $3 \%$ of patients treated with ICls [16-18].

There is a difference cutaneous toxicities between PD-1/PD-L1 inhibitors and CTLA-4 inhibitors. Psoriasis, pemphigoid, and cutaneous sarcoidosis were mainly reported with PD-1/PD-L1 inhibitors, whereas Sweet syndrome and erythema nodosum were almost exclusively observed with CTLA-4 inhibitors [19]. The most common side effect reported with $\mathrm{ICls}$ is pruritus $(7,8)$, with an estimated incidence between 11 and 47\% [10,20]. Pruritus, in the absence of rash occurs in 11 to $18 \%$ of patients treated with PD-1 inhibitors and up to $30 \%$ of patients treated with anti-CTLA-4 inhibitors $[7,21,22]$. Pruritus can deeply affect quality of life of patients and may lead to treatment discontinuation. However, physiopathology and etiology of $\mathrm{ICl}$-related pruritus has been unknown [1].

Pembrolizumab, nivolumab, ipilimumab, and cemiplimab were caused pruritus in Salinas study [1]. It's appeared after a mean of 8.1 months after ICls initiation treatment and it was diffuse in $48 \%$ of cases [1]. It is essentiel to consider prodromal bullous pemphigoid in the evaluation of severe and refractory pruritus. Patients are generally treated with topical anti-pruritics such as camphormenthol ,topical steroids, anti-histamines, and occasionally other anti-pruritic drugs such as pregabalin or gabapentin, opioid antagonists such as naloxone and naltrexone, and the neurokinin-1 receptor antagonist aprepitant; phototherapy can also used $[13,22,23]$. The treatment prescribed for patients who present pruritus was emollients, antihistamines and topical steroids with favorable evolution of symptomatology [1]. Other skin diseases reported in this study in order of frequency of occurrence in $21.5 \%$ of cases were: vitiligo, eczema, maculopapular exanthema, psoriasis lichen, and folliculitis and urticaria [1].

Only severe and debilitating cases of pruritus require discontinuation of immunotherapy and systemic steroids [23]. Cutaneous rash is reported in $24 \%$ of the patients treated with ipilimumab, in $15 \%$ of those receiving antiPD- 1 and in $40 \%$ with the combination of nivolumab and ipilimumab [24,25]. Vitiligo is observed in about $8 \%$ of patients with metastatic melanoma treated with anti-PD-1 or with the combination of checkpoint inhibitors, but is rarely with ipilimumab alone [26]. The evaluation of severity of skin adverse events must be careful by the physicians and needs physical examination including the mucosal areas, and appreciation of the general status of the patient (fever, ...), and if needed, a biological checkup [2].

It is important to eliminate the possibility of a dermatological emergency such as drug rash with eosinophilia and systemic symptoms (DRESS), acute febrile neutrophilic dermatosis (Sweet syndrome), StevensJohnson syndrome or toxic epidermal necrolysis (TEN). In these life-threatening situations, the treatment with $\mathrm{ICl}$ should be definitively discontinued, the patient necessit emergency hospitalisation, and symptomatic treatment should be initiated immediately by a dermatologist [2].

\section{Management of Cutaneous rash $[2,27]$}

For grade 1 (mild): Macular or papular eruption ,asymptomatic lesions

Treatment by immunotherapy can be continued and symptoms can be treated with topical steroids, oral antihistamines.

For grade 2 (moderate) : Pruritic symptoms $\leq 50 \%$ of skin surface

treatment with immunotherapy drugs can be continued but should be checked weekly for improvement. If not resolved, treatment should be discontinued until the skin lesions has reverted to grade 1 . Symptomatic treatment consists of topical steroid cream, oral antihistamines and oral steroids: prednisolone $1 \mathrm{mg} / \mathrm{kg} /$ day x 3-7 days-max: $60 \mathrm{mg} /$ day or equivalent depending on severity and extent of rash. If the symptoms persist more than 5 days or worse or relapse, we omit the next dose of immunotherapy and we start oral corticosteroid therapy, if not commenced already and topical emollient. The monitoring must be daily by the physician.

For grades 3/4 (Severe or life threatening): defined as any of the following

Citation: Mohamed réda KHMAMOUCHE ${ }^{1,2}$, Choukri Elmhadi ${ }^{1}$, Tarik Mahfoud ${ }^{1}$, Rachid Tanz ${ }^{1}$, Lamiaa Amaadour ${ }^{2}$, Aziz Bazine ${ }^{3}$, Mohamed Fetohi ${ }^{3}$, Nawfel Mellas ${ }^{2}$ and Mohamed Ichou ${ }^{1}$. Skin Toxicities of Immune Check Point Inhibitors in Solid Tumors and Managment: Review of Literature. 
$>50 \%$ skin surface, generalised, exfoliative, ulcerative or bullous dermatitis

The severe skin $\mathrm{AE}$ require immediate interruption of ICls, until these are back to grade 1 . Treatment includes topical emollients cream, oral antihistamines and high strength topical steroids . Systemic corticosteroids $0.5-1$ $\mathrm{mg} / \mathrm{kg}$ can be considered, depending on the severity of the symptoms. Patients should be need urgently a biopsy for confirmation of diagnosis and admitted to intensive care unit for monitoring. Treatment consists of high dose intravenous corticosteroids (methyl prednisolone $1-2 \mathrm{mg} /$ $\mathrm{kg}$ with tapering when the toxicity resolves to grade1. We must not forget IV antibiotics if patient had signs of infection.

If symptoms resolve or improve to grade 2: discontinuation of immunotherapy must be permanent and we initiate corticosteroid taper over $\geq 2$ months $[2,27]$.

\section{Conclusion}

Immunotherapy is associated with immune-related adverse events (irAEs).Skin irAEs are among the most frequent toxicities observed within the first few weeks after initiation of ICls. Severe cutaneous lesions can become life-threatening that's why oncologists must know how to recognize these lesions and refer the patient to the dermatologis. These dermatological toxicities can be managed effectively by using established international guidelines

\section{Conflit of Interest}

None

\section{References}

1. Neumosur (2020). Documento General COVID-19. Asociación de Neumología y Cirugía Torácica del Sur, 2020.

2. Diaz C, Gonzalez G, Maryla Y Lopez HI. COVID-19 en Pediatría. ¿Qué se sabe? Rev haban cienc méd [online]. 2021, 20(1): e3637.

3. H Harapana, Naoya I, A Yufika, W Winardif, S Keamg, et al. Coronavirus disease 2019 (COVID-19): A literature review. Journal of Infection and Public Health, 2020; 13(5): 667-673

4. Zhang C, Chu H, Pei YV, Zhang J. Laboratory effects of COVID-19 infection in pregnant women and their newborns: A systematic review and metaanalysis. Front Glob Women's Health, 2020; 2: 647072.

5. Auad J, Cerutti J, Cooper GL, Lozano N, Deltrozzo J, et al. Estructura de la placenta y su impacto en la transferencia de la inmunidad materno-fetal. revisión en mamíferos domésticos. Rev Methodo, 2018; 4(2): 52-62.

6. Huaheng Mo, Ming Wang, Mengmei Wang, Yi Han. Detectable antibodies against SARS-CoV-2 in newborns from mothers infected with COVID-19 at different gestational ages. Pediatrics and Neonatology, 2021; 62(3): $321 \mathrm{e} 323$.

7. Salazar Torres, D Ávila Gamboa. (2014, 5 agosto). Inmunología perinatal. Inmunología perinatal. Universidad de Ciencias Médicas de Villa Clara-Cuba.

8. O Limay Ríos, C Dávila Aliaga, R Álvarez Carrasco, M Espinola Sánchez. Transmission Perinatal de SARS-COV-2: Necesidad de Estudio Ante Posible Infeccion Congenita. Transmission Perinatal de SARS-COV-2. (2020, 5 septiembre).

9. Vacunas SARS-COV2 marzo 2021. Nefrologiaaldia.

10. Vacunas contra COVID-19 Bvsalud.org. [ octubre de 2021].

11. CDC. Consideraciones de vacunación para personas embarazadas y en periodo de lactancia Cdc.gov. 7, 2021.

12. G Izquierdo, D Martíneza. Revista médica clínica las condes. Vacunas e inmunizaciones En recién nacidos y recién nacidos prematuros. (2020, 12 abril).

13. Gray KJ, Bordt EA, Atyeo C, Deriso E, Akinwunmi B, et al. Coronavirus disease 2019 vaccine response in pregnant and lactating women: a cohort study. Am J Obstet Gynecol, 2021; 225(3): 303.e1-303.e17.

14. Perl SH, Uzan Yulzari A, Klainer H, Asiskovich L, Youngster M, et al. SARS-CoV-2-specific antibodies in breast milk after COVID-19 vaccination of breastfeeding women. JAMA, 2021; 325(19): 2013-2014.

15. Shabir A, Madhi, Clare L, Cutland, Locadiah Kuwanda, et al. Influenza vaccination of pregnant women and protection of their infants, 2015; 371(10): 918-931.

16. Inmunovigilancia: Evaluación de la inmunogenicidad de las vacunas anti-COVID-19 en el marco de la farmacovigilancia intensiva-Protocolo Bogotá, Distrito Capital Formulación Pfizer/BioNTech. saludcapital.gov. co. 2021.

Citation: Mohamed réda KHMAMOUCHE ${ }^{1,2}$, Choukri Elmhadi ${ }^{1}$, Tarik Mahfoud ${ }^{1}$, Rachid Tanz ${ }^{1}$, Lamiaa Amaadour ${ }^{2}$, Aziz Bazine ${ }^{3}$, Mohamed Fetohi ${ }^{3}$, Nawfel Mellas ${ }^{2}$ and Mohamed Ichou ${ }^{1}$. Skin Toxicities of Immune Check Point Inhibitors in Solid Tumors and Managment: Review of Literature. 